In the context of current political and social developments, where the national group is not so clearly defined and delineated, the state language not so clearly dominant in every domain, and cross-border flows and transfers affects more than a small elite, new patterns of language use will develop. This series aims to provide a framework for reporting on and analysing the lingustic outcomes of globalization and localization.

More information about this series at

http://springer.com/series/14830
Sender Dovchin . Shaila Sultana Alastair Pennycook

\section{Popular Culture, Voice and Linguistic Diversity}

Young Adults On- and Offline palgrave macmillan 
Sender Dovchin

Centre for Language Research

University of Aizu

Tsuruga, Japan

Alastair Pennycook

Faculty of Arts and Social Sciences

University of Technology Sydney

Ultimo, NSW, Australia

Shaila Sultana

Department of English Language

University of Dhaka

Dhaka, Bangladesh

\section{Acknowledgements}

A joint research and writing project such as this, spanning many different places-Bangladesh, Mongolia, Japan, Australia - and people, inevitably puts a strain on many others alongside the authors. We are very happy to finally see this fascinating and complex project into print, and we would like to express our immense gratitude to all those who have been part of this, participating, supporting, advising and making it all possible.

First and foremost, we would like to thank our research participants. This book would not have been possible without the valuable input of student participants of the National University of Mongolia, Ulaanbaatar, Mongolia, and University of Excellence (pseudonym), Dhaka, Bangladesh. They have given us access to their life and everyday conversations, making it possible for us to understand young adults' mobility and locatedness in a fluid global world and explore the diversity in their voices within the linguistic, cultural, social and spatial realities of their individual and collective lives.

We would like to thank our colleagues at our respective universities for their continued encouragement and support. They have believed in us and continually inspired us to reach excellence in our respective research: The University of Aizu, Japan: John Blake, John Brine, Younghyon Heo,

Printed on acid-free paper

This Palgrave Macmillan imprint is published by Springer Nature

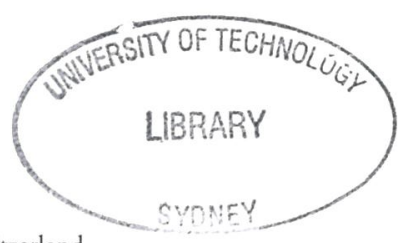


Emiko Kaneko, Yosuke Kira, Maxim Mozgovoy, Allan Nicholas, Merissa Ocampo, Moonyoung Park, Jeremy Perkins, Kim Rockell, Debopriyo Roy, Arifumi Saito, Julian Villegas, Ian Wilson, Kazuaki Yamauchi, Takako Yasuta. Amongst our many helpful and supportive colleagues at the University of Technology Sydney (UTS), we would like to thank in particular Liam Morgan, Emi Otsuji, Gloria De Vincenti, Nick Hopwood and Theo van Leeuwen. At the University of Dhaka: Dil Afroze Quader, and at North South University, Dhaka: Khaliquzzaman M. Elias.

In the broader context of writing this book, we sincerely thank our colleagues: Samy Alim, Jannis Androutsopoulos, Gary Barkhuizen, Tyler Barrett, Allan Bell, Adrian Blackledge, David Block, Jan Blommaert, Brook Bolander, Kingsley Bolton, Werner Botha, Suresh Canagarajah, Julie Choi, Angela Creese, Nik Coupland, Christian W. Chun, James D'Angelo, Ana Deumert, Kara Fleming, Ophelia García, John Hajek, Maria Harissi, Christina Higgins, Helen Kelly-Holmes, Zhu Hua, Dejan Ivković, Dariush Izadi, Marco Jacquemet, Jürgen Jaspers, Adam Jaworski, Rodney Jones, Martha Karrebæk, Brian King, Claire Kramsch, Sjaak Kroon, Ryuko Kubota, Samu Kytölä, Sara Laviosa, Jerry Won Lee, Sirpa Leppänen, Angel Lin, Stephen May, Tommaso Milani, Miguel Pérez Milans, Janus Møller, Bonny Norton, Tope Omoniyi, Ivan Panović, Joseph Park, Sari Pietikäinen, Ingrid Piller, Damian Rivers, Andrew Ross, Benedict Rowlett, Linus Salö, Elana Shohamy, Maria Grazia Sindoni, Lynn Mario Menezes de Souza, Max Spotti, Chris Stroud, Setiono Sugiharto, Bente Svendsen, Jos Swanenberg, Caroline Tagg, Steve Thorne, Ruanni Tupas, Clive Upton, Li Wei, Elina Westinen, Quentin Williams and Sue Wright. During the life of this project, we have been fortunate to have had many fruitful discussions with these remarkable colleagues on urban youth, popular culture, translanguaging, transglossia and multilingualism. They have taken our thoughts in different directions with their constructive feedback and opinions, and helped us to bring greater rigour to our research.

We are sincerely grateful to the Endeavour Postgraduate Scholarship, Australian Education International, the Australian Research Training scholarships scheme, a research grant of the University of Aizu and UTS International Research Grant and UTS President Scholarships for funding our research projects. The research studies in Mongolia and Bangladesh were funded as a part of Ph.D. research projects done at UTS.

We would like to dedicate the book to our families, specifically to the loving memory of Erdenechimeg Perliijantsan (mother of Sender), who sadly passed away prior to the completion of this book; Wilson Dovchin Dring (son of Sender); David Dring (father of Wilson); Prof. Dovchin Yondon (father of Sender) and Ulemj Dovchin (sister of Sender), who offered their unconditional love and support. We would also like to dedicate it to the fond memory of Md. Sulaiman Mia (father of Shaila), who saw the initial drafting of the book chapters, but could not see its completion; and Suraiya Begum (mother of Shaila), Aqeeb Jawad Ahmed (son of Shaila), Areebah Ozara Elham (daughter of Shaila) and Faisal Ahmed (husband of Shaila) for the compassion and kindness they have shown and cooperation they have given during the writing of the book. And thanks to Dominique Estival for her continued support of all our work. Our families deserve our heartfelt gratitude for the sacrifices and compromises they have made in order to accommodate the book project into our life. We are also grateful to our book cover model Khulangoo Unurbat, her mother Bolormaa Shinjee and the photographer Nomin.

Finally, we are also thankful to publishers who have allowed us to use some data and discussions which came out earlier as articles and book chapters. This book is derived in part from the articles published in:

Dovchin, S. (2015). Language, multiple authenticities and social media: The online language practices of university students in Mongolia. Journal of Sociolinguistics, 19(4), 437-459. Copyright <Wiley>, available online: http:// onlinelibrary.wiley.com/doi/10.1111/josl.12134/full.

Dovchin, S. (2017). Uneven distribution of resources in the youth linguascapes of Mongolia. Multilingua, 36(2), 147-179. Copyright <De Gruyter>, available online: https://doi.org/10.1515/multi-2015-0065.

Dovchin, S., Sultana, S., and Pennycook, A. (2015). Relocalizing the translingual practices of young adults in Mongolia and Bangladesh. Translation and Translanguaging in Multilingual Contexts, 1(1), 4-26. Copyright <John Benjamins>, available online: http://jbe-platform.com/ content/journals/10.1075/ttmc.1.1.01dov. 
Dovchin, S., Sultana, S., \& Pennycook, A. (2016). Unequal translingual Englishes in the Asian peripheries. Asian Englishes, 18(2), 92-108. Copyright $<$ Taylor \& Francis>, available online: doi: http://dx.doi.org/10.1080/ 13488678.2016.1171673.

Sultana, S. (2014a). Heteroglossia and identity of young adults in Bangladesh. Linguistics and Education, 26, 40-56. Copyright <Elsevier>, available online: https://doi.org/10.1016/j.linged.2014.01.009.

Sultana, S. (2014b). Young adults' linguistic manipulation of English in Bangla in Bangladesh. International Journal of Bilingual Education and Bilingualism, 17(1), 74-89. Copyright <Taylor \& Francis>, available online: http://dx.doi. org/10.1080/13670050.2012.738644.

Sultana, S. (2015). Transglossic language practices: Young adults transgressing language and identity in Bangladesh.Translation and Translanguaging in Multilingual Contexts, 1(2), 68-98. Copyright <John Benjamins>, available online: http://jbe-platform.com/content/journals/10.1075/ttmc.1.2.04sul.

Sultana, S. (2016). Language and identity in virtual space: Reconceptualisation of ELF. Journal of Asian Pacific Communication, 26(2), 216-237. Copyright $<$ John Benjamins $>$, available online: http://jbe-platform.com/content/ journals/10.1075/japc.26.2.03sul.

Sultana, S., \& Dovchin, S. (2017). Popular culture in transglossic language practices of young adults. International Multilingual Research Journal, 11(2), 67-85. Copyright <Taylor \& Francis>, available online: doi: http://dx.doi. org/10.1080/19313152.2016.1208633

Sultana, S., Dovchin, S., and Pennycook, A. (2013). Styling the periphery: Linguistic and cultural takeup in Bangldesh and Mongolia.Journal of Sociolinguistics, 17(5), 687-710. Copyright <Wiley>, available online: http://onlinelibrary.wiley.com/doi/10.1111/josl.12055/full.

Sultana, S., Dovchin, S., and Pennycook, A. (2015). Transglossic language practices of young adults in Bangladesh and Mongolia. International Journal of Multilingualism, 12(1), 93-108. Copyright <Taylor \& Francis>, available online: doi: http://dx.doi.org/10.1080/14790718.2014.887088.

\section{Contents}

\section{Language, Culture and the Periphery}

2 Transglossia: From Translanguaging to Transglossia

3 Transglossia and Music: Music, Sound and Authenticity

4 Transglossia and Films: Sense of Affiliation

5 Transglossia and Sports: Men Talk and Masculinity

6 Cyber Transglossia: Unequal Resources

7 Transglossia and Cultural Jamming: Parodies and Group Solidarity

8 Popular Culture, Transglossic Practices and Pedagogy

Index 


\section{Language, Culture and the Periphery}

This book deals with the language of young adults in both online and offline environments. The very fact that we can talk of 'offline' environments points to the salience of life online: for many young people today, being online-on Facebook, Twitter, What's App, texting, chatting, Skyping — is part of everyday life. You do not set aside a time of day to 'go online'-you simply are online much of the time. It no longer makes sense to view this as some alternative and lesser (virtual) reality: being online is as real as anything else. These online and offline worlds are also interlinked, with offline worlds becoming part of the online and online affecting face to face interactions. So this is the first context of this book: the intertwined worlds of online and offline conversations, postings, comments and chats.

Why young adults? By and large, this is where the action is, and these are also the people who interest us as educators. These are the people who have grown up with the new technologies, who learned to 'swipe' a page at an early age, whose fingers move comfortably across mobile keyboards, messaging, adding emoticons, chatting, watching and multitasking. They are also at an age of flexibility, happy to try stuff out, exploring identities, messing around with language and engaged with 
popular culture. They are sitting in our university and other classes, watching us (now and then), checking their mobile devices (more often) and living in multiple linguistic, cultural and spatial worlds. These are also the consumers of popular culture, people for whom music, TV dramas, films form not just a backdrop to their daily lives, not just a pastime when they are not doing something else, but a fabric around which parts of their lives are built.

The book is about three particular aspects of this young adult action. First, we are interested in the way they use, mix and mash up language. In line with contemporary trends in sociolinguistics, we no longer view this through a lens of bilingualism or code-mixing, but rather take this use of multiple linguistic resources as the norm. Young people are exposed to and take up a range of linguistic and broader semiotic resources in their daily communications. These young adults are also the drivers of innovation, the setters of new trends, the ones bending the rules, making up the terms and changing the way language works. As they communicate in and across various social groups, these new trends may move rapidly around the globe, getting picked up and passed on from online forum to Twitter account, from YouTube clip to café discussion, while at the same time they may also define subcultural language uses, showing who is in and who is out, who knows how to mess with language and image in this way and who does not.

Second, we are interested in the sources from which they draw these multiple resources. While language classes, travel and other more traditional modes may provide some of the input into their linguistic repertoires, it is a popular culture that plays a major role here. These young adults tend to be highly engaged with music, dance, film, gaming and multiple forms of popular culture, which provide not only content to be discussed or parodied but also voices and linguistic resources. They take up and play with the voices of popular culture, and in so doing gain access to a range of languages, ideas and ways of articulating the world. The linguistic creativity, parody and play, therefore, involve voices, sounds, images and phrases drawn from a variety of cultural forms, from well-known songs to film scenes, from information about sport stars to details about technology.
Third, we are interested in how these relations get played out in the Asian periphery. Much has been made of the diversity brought about by migration to European cities, but much less attention has been paid to the diversity that now occurs in contexts marked by online rather than physical mobility. The Asian focus allows us to turn the attention away from Europe and North America, which are so often the focus of such studies and instead to look at the vibrant and emerging Asian scene, which again, we might suggest is where the action is, as Asian and non-Asian forms of popular culture circulate through the digital pathways. The peripheral focus adds a further dimension to this, allowing us to look in depth at two contexts that have to date received little attention in the literature: Bangladesh and Mongolia. At the same time, this peripheral focus draws attention to questions of access and distribution: Who gets to play around with language and culture in what contexts?

\section{Eye Shopping: güzel çanta}

Before exploring these themes of language mixing, popular culture, digital literacies and the periphery in greater detail in the following sections, a couple of examples may serve to show the kind of thing that is going on. Here in Excerpt 1.1, for example, is a Facebook (FB) posting by Altai, a 20-year-old female third-year chemical engineering student at the National University of Mongolia. The examples below have been

Excerpt 1.1 Language guide: regular font = Mongolian; italics = English;

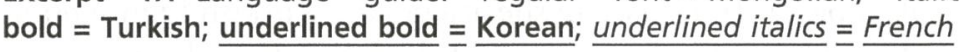

\begin{tabular}{|c|c|}
\hline Facebook status & Translation \\
\hline $\begin{array}{l}\text { 1. Altai: Undraa! çok } \\
\text { güzel çıkmışsınız } \\
\text { tatlım...zondoo unsey } \\
\text { hairtai shuu... } \\
\text { annesine benziyor...love } \\
\text { n miss }\end{array}$ & $\begin{array}{l}\text { Altai: Undraa! you look so pretty sweetie... lots of } \\
\text { kisses love you...looking like your mother love } n \\
\text { miss }\end{array}$ \\
\hline $\begin{array}{l}\text { 2. Altai: Ai syopping @ } \\
\text { Louis Vitton... } \\
\text { güzel çanta... }\end{array}$ & $\begin{array}{l}\text { Altai: Window shopping @ Louis Vuitton...lovely } \\
\text { bags... }\end{array}$ \\
\hline
\end{tabular}


retrieved from Altai's daily FB wall status updates, where she actively posts about her daily activities, including the places she has been to or the photographs she has taken, or the movies she has seen (Dovchin 2015). A general guide to transcription conventions is provided at the end of the chapter, while specific guides to language identification conventions are provided before each excerpt. All data examples were translated from Mongolian and Bangla into English by the authors, and all the names used for the research participants are pseudonyms to protect their real identities.

In the first line, Altai uploads a photograph of her friend (Undraa) with a caption combining Turkish and Mongolian in Roman script and a popular transnational online phrase 'love $\mathrm{n}$ miss' to show affection. This is a typical example of her Facebook repertoire, where the extensive incorporation of Turkish is often integrated either with Mongolian or English resources. As will become clear throughout this book, the identification of a linguistic and cultural origin of such resources is rarely without problems: To say here that 'love $\mathrm{n}$ miss'(a common globally available phrase) is in English, or that 'Ai syopping' (a phrase from Korean English) is Korean, or that 'Louis Vitton' (a popular brand name) is French is not so much to tie such terms to a language of origin, but rather to point to the already-mixed cultural and linguistic resources these young people draw on (Dovchin 2015).

The rather unexpected use of Turkish here can be explained by her high school experience, which has resulted in the development of linguistic skills in Turkish and English. Altai is originally from Khentii Province in the East of Mongolia, bordering Russia. Her family moved to the capital, Ulaanbaatar (UB), where she attended a Turkish high school. Initially, Turkish high schools were established in Mongolia from the mid-1990s, when large numbers of Turkish people started coming to the country. Today, there are five Turkish schools still operating in Mongolia. Turkish schools are well known for their Turkish and English-medium teaching, targeting natural science specialized studies, and are regarded as some of the best high schools in Mongolia, with extremely strict entrance examinations. Students who gain entrance are often provided with a comfortable dormitory and free-of-charge study materials. Many graduates of these schools get impressively high scores in state examinations. More recently, these schools have also become the target of controversy due to their alleged association with the exiled Muslim cleric Fethullah Gülen, who is now blamed for masterminding the military coup in Turkey. In fact, it is alleged that Gülen-associated Turkish schools are currently operating in 173 countries. Since the failed military coup attempt, Turkey has escalated its all-out campaign to put pressure on dozens of countries around the world to shut down Gülen-linked Turkish schools.

In line 2, Altai updates her Facebook status, echoing the anglicized Korean expression 'Ai syopping' ('아이쇼핑'; 'eye shopping') for 'window shopping', the online symbol '@' to show her location at the French handbag store Louis Vuitton, accompanied by Turkish, 'güzel çanta' ('lovely bags'). The use of various Korean-oriented resources is not so much a result of a knowledge of Korean, but rather, according to Altai, an obsession with Korean dramas. When she was studying in Ankara, Turkey, for a year as an exchange student, Altai was extremely homesick. To overcome her loneliness, she started watching Korean TV dramas downloaded from Internet TV channels, subtitled in English. Although her obsession with Korean dramas is associated with her Turkish experience, this also points to the wide popularity of Korean TV dramas in Mongolia - and elsewhere since the 1990s. The boom of Korean TV dramas has dominated the Mongolian commercial broadcasting scene, popularizing Korean movie stars and K-pop singers amongst the urban youth population in Mongolia (Dovchin 2015).

Because of her obsession with Korean TV dramas, Altai frequently imports Korean resources into her own speech. She has also travelled to Seoul a few times with her family. Thus, although Altai does not by her account speak Korean, she incorporates Korean-oriented semiotic resources borrowed from her favourite Korean movies (Dovchin 2015). Altai's use of English, Korean, Mongolian and Turkish, then, already points to a number of important concerns for this book: we see linguistic and other semiotic resources combined in what appears a quite casual and carefree manner. While some of these combinations and usages may appear quite unexpected, for her and the community to which she is appealing, they are not particularly noteworthy or strange: many of her FB friends have related repertoires of resources. Popular cultural 
resources may be of many kinds-from shopping to Korean dramasand may reveal aspects of the particular life history, class location and interests of the participants (her use of Turkish and comments on LV bags are clearly marks of socio-economic privilege). These resources are also quite diverse, and contrary to assumptions about the domination of English language and American cultural forms, may include a range of others from Korea, Japan, China and other parts of Asia. This in turn has implications for how we understand the Asian periphery: as Choi (2012, 2016) shows, Korean dramas have become a linguistic and cultural resource for many-both young and old, Asian and non-Asian — and circulate widely through different channels.

\section{Language and the Periphery}

Our focus on Mongolia and Bangladesh enables us to highlight several aspects of the contemporary global, Asian, linguistic and popular cultural scenes. Significantly different in terms of size (Mongolia is 10 times bigger), population (Bangladesh has 50 times more people), population density, histories, economies, elevation, climate and much more, these two countries nevertheless share a similar status as seemingly peripheral players both globally and in relation to a rapidly changing Asia. Each sits uncomfortably close to one of the Asian giants, India and China, with various ramifications-for example, Chinese mining interests are affecting the social and economic fabric of Mongolia, while the Bollywood film industry seeps into daily life in Bangladesh-and each has also suffered periods of colonization (by the Russians and the British, respectively), with implications for the roles played by Russian-oriented and English language and music. As we have already seen above, however, it is always more complex than a simple analysis along historical or political economic lines would suggest, with other players such as Turkish or Korean dramas becoming part of the daily lives of young Mongolian adults.

Our focus is not on a comparison of the two contexts but to see how online consumers-those with the economic and cultural capital to access various media-become non-peripheral participants in a variety of cultural and linguistic flows while also negotiating their own social and cultural locations. The notion of the periphery needs some further discussion. As we can observe from Altai's eyeing of LV bags, and what we might call cosmopolitan use of English, Korean and Turkish alongside Mongolian, to be in the periphery is clearly a relational prospect: within every centre, there are peripheries, and within every periphery, there are centres. Indeed, as a modernist binary, the centre-periphery construct has been widely critiqued for its oversimplified framing of global relations and weakness in dealing with multiplicity, relativity and mobility: 'The global cultural economy has to be seen as a complex, overlapping, disjunctive order, which cannot any longer be understood in terms of existing centre-periphery models' (Appadurai 1996, p. 32; cf. Appadurai 1990, 2000).

It is on such grounds that sociolinguistic models such as Phillipson's linguistic imperialism have been strongly critiqued. Based on the classic centre-periphery model of imperialism that describes the 'Centre's attempt to control people's consciousness' through the 'Centre's cultural and linguistic penetration of the Periphery' (Phillipson 1992, p. 53), Phillipson mapped language relations onto this broad model of political economy. As many recent accounts have shown, however, we need a more multifaceted model. In the context of the Philippines, as Martin (2014, p. 53) observes, centre and periphery relations are played out on local levels, comprising for example an inner circle 'of educated, elite Filipinos who have embraced the English language', an outer circle who may be aware of Philippine English as a variety but are 'either powerless to support it and/or ambivalent about its promotion' and an expanding circle for whom the language is 'largely inaccessible'.

More generally, we need to take seriously Blommaert's (2010, p. 20) injunction to approach the sociolinguistics of globalization in terms of a 'chequered, layered complex of processes evolving simultaneously at a variety of scales and in reference to a variety of centres'. If a sociolinguistics of globalization is to deal in terms of the periphery, it needs to avoid doing so through centrist eyes and avoid the exoticization of the periphery. The challenge is to encompass an understanding of the multiplicity and relativity of centres and peripheries, and to focus on processes of centralization and peripheralization (Pietikäinen and 
Kelly-Holmes 2013). As we have suggested elsewhere, an understanding of the styling of the periphery in countries located geographically, politically and economically on the Asian periphery, such as Bangladesh and Mongolia, can show how young people use linguistic and cultural resources to stylize and reconfigure their own location, which not only 'relocalizes cultural forms in these contexts but also relocalizes assumed traditions in the context of a flow of diverse cultural forms' (Sultana et al. 2013, p. 705). We need to account not only for flows and mobilities, nor only for macroformations of the global economy, geographical positioning and language commodification, but also the operations of globalization from below (the workings of local, informal, cultural and linguistic formations).

\section{Boys from the Periphery: 'Hey Babes, Come on!'}

A further example will help shed light on some of what we are looking at here. Excerpt 1.2 shows the common use of linguistic and cultural resources fashioned by young adults' engagements with different genres of popular culture. These are again shaped by socio-economic background and demographic locations that have influenced the nature of their exposure to popular culture. The participants in Excerpt 1.2 study at an expensive private university in a posh area of Dhaka, the capital of Bangladesh, but they do not belong to the privileged upper-echelon of the society. Both Nayeem and Ashiq had their earlier education in rural schools, the former in Noakhali, in north-eastern Bangladesh, the latter in Pabna, in north-western Bangladesh. Shamim was born and brought up and went to school in Chittagong, the second largest city in Bangladesh. ${ }^{1}$ All three are majoring in Business Administration at the University of Excellence (UOE). They are chatting, while looking at the students walking past the courtyard, their favourite hang-out on campus ${ }^{2}$ (see the transcription guide at the end of the chapter).
Excerpt 1.2 Language guide: regular font $=$ Bangla; italics $=$ English

\begin{tabular}{|c|c|}
\hline Casual conversation & Translation \\
\hline $\begin{array}{l}\text { 1.Ashiq: ((looking at the female } \\
\text { students walking by)) Hey BABES, } \\
\text { come on! }\end{array}$ & $\begin{array}{l}\text { Ashiq: ((looking at the female students } \\
\text { walking by)) Hey BABES, come on! }\end{array}$ \\
\hline $\begin{array}{l}\text { 2.Shamim: ((looking at the girl Nayeem } \\
\text { says that he has chosen for himself)) } \\
\text { OH MY G::O::D /ga:d/!!!!! }\end{array}$ & $\begin{array}{l}\text { Shamim: ((looking at the girl Nayeem } \\
\text { says that he has chosen for himself)) } \\
\text { OH MY GOD /ga:d/!!!! }\end{array}$ \\
\hline $\begin{array}{l}\text { 3.Nayeem: ((losing sight of the girl)) } \\
\text { hai, hai ((sound of anxiety)), koi galo? } \\
\text { dosto, kisu akta koira de!!! }\end{array}$ & $\begin{array}{l}\text { Nayeem: ((losing sight of the girl)) Alas } \\
\text { ((sound of anxiety)) where has she } \\
\text { gone? Mate, do something!!! }\end{array}$ \\
\hline $\begin{array}{l}\text { 4.Ashiq: ((as if he is trying to draw the } \\
\text { attention of the girl Nayeem is } \\
\text { looking for)) < IIla::ve you go::. IIla::: } \\
\text { velyou go::: ((in a melodramatic } \\
\text { tone)). I/la::ve you go::: > ((breaks into } \\
\text { laughter)) }\end{array}$ & $\begin{array}{l}\text { Ashiq: ((as if he is trying to draw the } \\
\text { attention of the girl Nayeem is } \\
\text { looking for)) I love you, oh you! I love } \\
\text { you, oh you! ((in a melodramatic } \\
\text { tone)). I love you, o you! } \\
\text { ((breaks into laughter)) }\end{array}$ \\
\hline
\end{tabular}

Here, Nayeem uses a variety of linguistic resources gathered from diverse genres of popular culture. The set expressions 'hey', 'babe' or 'I love you', commonly found in Indian and Western films and songs, point to these participants' use of popular culture as a source of linguistic material. Nayeem favors English expressions, such as 'babe', 'oh my god', 'I love you', 'oh no', 'awesome' or 'what a lovely [sic]', this latter, he explains, apparently derived from 'what a lovely shot' heard in cricket commentaries. In interviews and focus group discussions conducted in the ethnographic research, Ashiq and Nayeem repeatedly mention that they lack fluency in spoken English, but like using set expressions because they feel 'cool', fashionable', 'smart', 'bold' and 'confident'. They prefer creating a feel of transnational 'cool talk' using English (Blommaert 2014). Their inclination towards transnational popular expressions also reflects the social ideologies that encourage these young adults to produce these expressions as a vehicle of sophistication and coolness (Dovchin et al. 2016; Sultana 2013; Leppänen et al. 2009).

Ashiq adds a Bangla word 'go' at the end of 'I love you' in line 4. 'go' is usually used for drawing attention as in 'ogo'(O you!), 'ha go'(Look here!) or in 'ke go'(Who are you?). It is also used as a suffix in invocations or lamentations, at the end of 'ma'(mother) as in 'mago' or Allah (lord) 
as in 'Allahgo'. The coexistence of 'I love you' and the Bangla word 'go' side-by-side is unusual and unexpected, but can be seen as an example of everyday linguistic creativity (Swann and Maybin 2007). The pronunciation is exaggerated and enunciated with stress, and Ashiq's utterance is theatrical, similar to what we call filmic ways of speaking (cf. Chap. 4). With the stylization of 'I love you' and combination of English 'I love you' with Bangla 'go', Ashiq tries to draw attention of passing-by female students and simultaneously creates the desired dramatic effect amongst his friends (male hassling of women is often aimed more at other males than at the women themselves, who nonetheless have to suffer such public harassment).

Ashiq and Nayeem may have acquired linguistic and cultural texts from popular culture, but the means by which they realize this performance is linked to their educational and demographic backgrounds. Blommaert and Backus (2013) identify individual repertoires as 'indexical biographies'-carrying marks and associations of time and space of individual life trajectories. Their 'biographically ordered repertoire of linguistic resources' which include English too are dynamically 'shaped by complex life trajectories' (Tagg 2016, p. 60). The pronunciation of 'babes' is distinctly different from English /beib/, sounding more like / beb/ and with a more prominent /b/ than the softer English /b/. The diphthong /ei/ is replaced by a short vowel /e/, as has been observed in other Bangladeshi speakers (Hoque 2011). Vowel lengthening and similar enunciated pronunciation are observed in 'god' in line 2, which approximates the pronunciation of /gad/ in American English. In line 4, / $\Lambda /$ sound in love is replaced with a Bangla vowel sound /a/ and is lengthened. While the vowel lengthening allows Ashiq to express the desired theatricality and the pronunciation of /gad/ indicates his exposure to popular culture, his pronunciation of /beb/ and /lav/ sounds more like 'banglicized English', i.e. spoken English that approximates Bangla or regional varieties of Bangla in segmental and suprasegmental features (Sultana 2014a).

Because of the wide acceptance of the association of English with the privileged social class and pronunciation as a marker of better education in urban schools and colleges, pronunciation approximating Standard English has become the indicator of individual sociocultural, demographic and educational background in the context of Bangladesh. Spoken English that sounds more like Standard English indicates a privileged upbringing and education in urban centres. By contrast, 'banglicized English' is marked by phonological features of Bangla and varieties of Bangla widely used in different regions in Bangladesh. Consequently, 'banglicized English' is looked down upon in an urbanized context like Dhaka, having associations with speakers who have come to the city from rural areas or have had education in rural schools and colleges. Thus, the segmental features of these English words give a better understanding of 'unequal Englishes' (Rubdy 2015; Dovchin et al. 2016; Sultana 2014a) as situated and realized in everyday conversations.

Nayeem and his friends are strategic in terms of their use and the kinds of affiliation, disaffiliation, inclusion and exclusion they develop in their language practices. In their use of 'banglicized English', Ashiq and his friends are marked out from their urban counterparts, who may, by contrast, use a form of 'anglicized Bangla', that is pronunciation of Bangla with English phonological and prosodic features, suggesting an affiliation with exclusive English-medium education in urban schools and colleges in Dhaka (Sultana 2014a). Nevertheless, with their use of few words in English derived from popular culture and recombination of these English words and phrases with a filmic way of speaking (cf. Chap. 4), they emerge with their own style of communication. These young adults, with their performance of streetwise cool young adult identity attributes, momentarily challenge the condescension, prejudice and discrimination affiliated with 'banglicized English' and the 'hick' identity attributes associated with it (cf. 4 2014a, 2016a; Dovchin et al. 2016). Finding themselves socially and linguistically disadvantaged, they use diverse forms of linguistic and cultural resources and strengthen their position in their immediate social landscape.

The English they use thus reflects their diverse exposure to different social landscapes, a transition from the least privileged education system in rural/provincial towns to an English-medium education system at a private university in the capital city. The English they use allows them to enact different facets of their identification discursively within the broader ideological framework of a society that is stratified by class, language, and educational and demographic backgrounds. However, the 
extent to which they can redefine their social positioning may be questioned (cf. Chapter 6). Here, then, we see several further implications for the discussion in this book: English, we know, often plays an important role in relation to popular culture and urban youth culture, and it is often used to give a sense of urban or global cool. And yet these English resources may equally locate people within a stratified world of unequal Englishes (Dovchin et al. 2016).

\section{Popular Culture and the Everyday}

As we have seen in the two examples above, popular culture seeps into the daily talk and lives of these young adults. These are not merely references to a song or a film but rather the use of language picked up through engagement with popular forms of entertainment that in turn index a larger world of people, places, languages and cultures. As we shall see further in the next chapter, these can include references to people, lines from films in Hindi, songs and much more. Before proceeding, however, we need to consider in greater depth the notion of popular culture. As we might note in the example above, as these young men call out to young women across a public space at their university, an engagement with popular culture may endow people with new cultural and linguistic resources, may allow them to take on new voices, to play new roles, to do things they would not do otherwise, but such take-up of popular culture may be equally crass, sexist, crude, unpleasant or many other things. Popular culture is not something to be uncritically celebrated.

Recent times have seen an upsurge in studies of the sociolinguistics of popular culture (Alim et al. 2009). While this in turn raises a number of questions about authenticity (what is the status of performance data as everyday language use?), a theme to which we return in Chapter 3, it is also worth turning a critical eye on popular culture itself (Lee and Moody 2012). A constant theme in discussions of popular culture has to do with its commercialization. In noting its role in the formation of identity, its connections to desire and its localities, we may romanticize the authentic, precommercialized forms of popular expression as a true original voice from the margins and overlook the forces of commercialization that render the local as popular. Popular culture may indeed be racist, homophobic or misogynist: its frequent articulations of heteronormative sexuality constantly position other sexualities as other. It can be crass, maudlin, simplistic, dull, tedious, overmarketed and reactionary (Pennycook 2010). And yet, to dismiss popular culture as shallow, commercial and conservative is to overlook several important points.

Different positions on the political spectrum, from conservative critics of low culture to leftist critics of mass culture, have often been strangely united in their denigration of the popular (Brantlinger 1983). A strong theme in Marxist-derived arguments equates popular culture with 'mass culture', and this in turn with ideological forms that subjugate working people. As Adorno (1975, p. 18) puts it, the 'total effect of the culture industry is one of anti-enlightenment, in which... enlightenment, that is the progressive technical domination of nature, becomes mass deception and is turned into a means for fettering consciousness'. From this point of view, mass culture serves both to distract working-class consumers from the realities of oppression and to refresh workers in their leisure time so that they are better able to participate in the workforce. This intellectual heritage clearly informs some of the critique of globalization and popular culture, which is seen 'in some gloomy Frankfurt School fashion, as the worldwide Americanization or standardization of culture, the destruction of local differences, the massification of all the peoples on the planet' (Jameson 1998, p. 57). Language and globalization are from this perspective a process of 'the homogenization of world culture... spearheaded by films, pop culture, CNN and fast-food chains' (Phillipson and Skutnabb-Kangas 1996, p. 439; italics in original).

The global dominance of certain languages and cultures is seen to be a submissive acceptance of their domination by an uninformed periphery, and to take up English is indeed to be a consumer of mass culture. From this 'dystopic, neo- or post-Marxist, political economic critique that still tends to employ...the metaphor of "penetrations"' (Jacquemet 2005, p. 259; and see Phillipson 1992, cited above) to sing in English, to watch English-language movies, to engage with English-medium popular culture is to act as an ideological dupe of the world system. To avoid such talk of penetration (with its uncomfortable sexual and cultural imagery), it has been common to employ the terminology of flows, yet here again, 
from a critical perspective, we need to be cautious about easy talk of cultural mobility: Are transcultural flows only one way, from the centre (particularly the USA) to the periphery? As Pennay (2001, p. 128) comments in his discussion of rap in Germany, 'Regrettably, the flow of new ideas and stylistic innovations in popular music is nearly always from the English-speaking market, and not to it'.

And yet, as studies of transcultural flows suggest, such movements and take-up of cultural forms may not be balanced but they are certainly complex (Pennycook 2007). While it is obviously important to understand the political economy of popular culture, to focus on questions of commercialization as well as access, dystopian accounts of passive consumerism may equally be seen as class-based denigrations of 'lower culture'. When Senegalese, Indigenous Australian or Mongolian hip-hop artists claim rap as their own, claim even that they have been doing it far longer than suggested by a simple account of origins and innovations, we are clearly dealing with a more complex set of relations than an analogy of 'spread' suggests (Pennycook and Mitchell 2009). Detailed accounts of the ways that cultural forms such as hip hop are taken up, changed and used in different cultural contexts suggest that we need at the very least to focus on the users, the people who are listening to and appropriating it if we are to understand the linguistic and cultural effects of popular culture.

Shusterman (2000, p. 49) mounts a strong argument for an understanding of the aesthetics of popular culture, suggesting that academic critics 'typically fail to recognize the multilayered and nuanced meanings of popular art' either because they are 'turned off from the outset and thereby unable to engage affectively with these works or because they lack an understanding of the cultural and intertextual references at play. Indeed, the more one reads critical accounts of popular culture and its consumption as a reflex of the global order-talk of homogenization, penetration and the destructive role of film, pop music and the use of English-the more such accounts appear to be elitist denigrations of the supposedly less educated rather than critical accounts of the production of inequality. More critically engaged explanations that are also more sympathetic to cultural difference have viewed popular culture as 'a significant and effective part of the material reality of history, effectively shaping the possibilities of our existence' (Grossberg 1992, p. 69). From this point of view, the study of popular culture is a sociological endeavour to understand class and culture.

As Scott (1999, p. 215) argues, the 'real question before us is whether or not we take the vernacular voices of the popular and their modes of self-fashioning seriously, and if we do, how we think through their implications'. It is this issue that is central to the themes of this book: How do we understand the ways in which language, popular culture and identity are intertwined? How do we take these seriously as part of the multilayered meanings, values and expressions that young people deploy to give meaning to their worlds (Grossberg 1989)? How do make sense of the ways in which young adults engage with popular culture, take pleasure in its many forms, take it up for their own purposes, use it as a means to experience and to locate themselves in the world? If we accept this view of popular culture as a crucial site of identity and desire, it is hard to see how we can proceed with any study of language, culture, globalization and engagement without dealing comprehensively with popular culture. In this sense, Sultana and Dovchin (2017, p. 1) point out that popular culture is 'not only a source of entertainment but a means to borrow voices, through which young adults enrich their language practices with various meanings and intentions'.

We need to consider the role of popular culture as oppositional force, as a counter both to the hegemony of what is deemed 'high culture' and to oppressive social forms. From Bob Marley to Bob Dylan (perhaps now recognized as a legitimate cultural performer since his award of the Nobel Prize for literature), popular music has also been a force in oppositional terms. Important too is an understanding of the ways in which popular culture is interpreted. Moffatt and Norton's (2005, p. 10) re-examination of an Archie comic text, for example, suggests that 'even a text that appears to be a simple mechanism for the reproduction of dominant ideas of gender relations may contain radical possibilities for investigating these very same relations'. As we shall see in later chapters (particularly Chapter 7), young adults may take up popular or traditional culture and may do all sorts of things with it. We cannot simply see it as passive consumption, nor as ideological manipulation. Nor should we romanticize it as some form of authentic voice of the people. The point is that it 
is part of the fabric of everyday life, and if we want to understand how young people in on- and offline interactions take up linguistic and cultural forms, we have to understand the critical role of popular forms of culture. As Lee and Moody (2012, p. 5) point out, 'Popular culture cannot exist without people in society, and a society without some form of pop culture is unthinkable'. Equally, an individual living in isolation would not create pop culture, since mass consumption and distribution, and expected or real economic gains, are vital components of pop culture. "This inherent connection between cultural artefacts and "people in society" makes pop culture all the more a research worthy topic for sociolinguists' (Lee and Moody 2012, p. 5).

\section{Online-Offline Relations}

Finally, let us turn in greater depth to the questions around being on- and offline. As suggested at the beginning of the chapter, the very fact that we can talk of 'offline' conversations points to the ubiquity of being online for young people. These two modes of interaction are now deeply intertwined, drawing on each other, with texts, conversations, images, devices all at play around each other. Indeed, we may have reached a point where the distinction is really no longer worth making, where the interconnectedness of people and technology, and the linguistic and cultural domains this affords, are not worth separating along these lines. It therefore no longer makes sense to stress the 'virtualness' of one reality over the other: being online is very real, and being offline is permeated by the online. Due to its widespread popularity, Facebook (FB) has started to play a significant role in the everyday digital literacy practices of people around the world (de Bres 2015; Bolander 2017). Desperately trying to keep up with the proliferation of online semiotic practices, scholarship on online digital literacy has emphasized linguistic diversity and semiotic heterogeneity as some of FB's crucial literacy characteristics (Leppänen et al. 2015). As Velghe (2015, p. 27) notes, 'Language and literacy are always the means to (obtain) voice ("to let one be heard and understood")'.

Facebook messages, from this point of view, can be viewed not so much as linguistic items, but rather as indexical objects that are meant to be used to socialize with others. These phatic FB exchanges are therefore better measured by the standards of the indexical order of linguistic resources, instead of by the standards of language only. While questioning the separability of language from other modes of communication on FB, Sharma (2012) also notes that the FB environment is a transmodal space, in which FB users redefine the role of English and other languages in relation to their existing online social relationships, innovatively transcending the meaning of English by not only mixing it with local language but also with other multimodal texts with both local and global media content. Put simply, digital literacy practices on FB often involve semiotic/linguistic creativity, with users re-entextualizating and relocalizing varied available signs and linguistic resources to create their own versions of digital literacy (Thorne 2013).

As Leppänen et al. (2015, p. 4) point out, superdiversity in social media is realized by "the mobility and mobilization of linguistic and other semiotic resources that are distributed, recontextualized and resemiotized in various ways in countless and rhizomatic digital media practices mushrooming on the internet'. Sharing an update on Facebook, for example, is a classic case of 're-entextualization' or 'resemiotization' (Varis and Blommaert 2015, p. 36). On the one hand, re-entextualization on FB refers to 'the process by means of which a piece of "text" [..] is extracted from its original context-of-use and re-inserted into an entirely different one, involving different participation frameworks, a different kind of textuality - an entire text can be condensed into a quote, for instanceand ultimately also very different meaning outcomes'. On the other hand, resemiotization refers to the "process by means of which every "repetition" of a sign involves an entirely new set of contextualization conditions and thus results in an entirely "new" semiotic process, allowing new semiotic modes and resources to be involved in the repetition process' (Varis and Blommaert 2015, p. 36).

As we have elsewhere suggested (Dovchin et al. 2015, p. 8), FB users make meaning 'not only through how they borrow, repeat and mimic certain linguistic resources available to them, but also through the ways they make new linguistic meanings within this complex relocalizing process'. Many recent FB studies have tended to concentrate on the relocalization/resemiotization processes of multimodal resources in 
creating superdiverse FB literacy practices. Phyak (2015) cautions, however, that FB digital literacy practices are not only about heterogeneity and fluidity, but also about homogenous and fixed identifications. As Otsuji and Pennycook (2010) argue in the context of metrolingualism (everyday urban multilingual practices), it is important to focus not only on the fluidity of linguistic practices but also on their fixity. Indeed, it is in the dynamic relation between fixity and fluidity that diversity needs to be understood. Facebook can be a discursive space that provides a critical and agentive place for people to reproduce their dominant offline identification and discourses (Phyak 2015). It is thus important for $\mathrm{FB}$ researchers not to miss out on crucial aspects of how and in what ways FB-based digital literacy practices can be connected to offline worlds and offline identity practices.

Part of our interest here, therefore, is in ways in which FB users' offline literacy and identity practices are filtered and leaked through their online literacy activities. Thorne (2013, p. 211) emphasizes that literacy educators should focus on the point where the forms of Internet-mediated activity are 'demonstrably embedded in, and functionally disassociable from, many offline communicative contexts and social networks'. The high frequency of interplay, as Thorne (2013, p. 211) adds, 'between onand offline activity has the potential to make developmentally and instructionally oriented use of mediated communication more relevant and meaningful due to its articulation with students' broader amalgam of integrated on- and offline lifeworld'. As Bucholtz and Hall (2016, p. 187) remark, research on how, for example, skateboarders relate physically to the uploaded videos of their performances (Jones 2009) shows not only how 'the body materializes in virtual environments but also how virtual environments affect embodiment offline'. Offline environments are not therefore more 'real' than 'virtual' online environments. Once we start to think in terms of networks of texts, artefacts, practices and technologies (Gourlay et al. 2013), the distinction between being online and offline, between real and virtual, and between paper text and screen text become much less important than an understanding of the relations amongst linguistic and cultural assemblages (Pennycook 2017).

\section{Conclusion}

In the following chapters, we will be developing many of these themes at greater length. We shall do this by focusing in each chapter on a particular domain of popular culture as it is taken up in everyday interaction. First, however, Chapter 2 provides a closer explanation of the idea of transglossia, which underpins the overall analytic framework used throughout this book. Through some initial examples of online and offline interaction, Chapter 2 highlights the transgressive nature (rather than just heterogeny or multiplicity) of semiotic diversity, and offers an integrated 'trans' analysis of language and popular culture using a set of analytic tools involving pretextual history, contextual relations, subtextual meaning, intertextual echoes and posttextual interpretation. This transglossic framework brings together recent work from a translinguistic orientation (questioning assumptions about the distinctions made between different languages) and a heteroglossic orientation (focusing on alterity, plurality, voice and otherness in language). This framework is central to the book since it allows us to engage in close textual analysis of a variety of young adults' semiotic practices while also exploring the implications of this mixed language use for the articulation of different positions through different voices drawn from popular culture.

We look in Chapter 3 at ways in which popular music-oriented resources are translingually created and reorganized by speakers. Popular music and its genres are crucial resources embedded within popular culture, enriching the linguistic creativity of young adults in multiple ways. The speakers take up and recreate popular music-oriented resources such as song lyrics, music videos and artists' images and styles for their own communicative purposes. This chapter also involves a discussion of the importance of the idea of authenticity for the sociolinguistics of popular music. Questions of authenticity have had a major role in sociolinguistics generally (Is this a moment of genuine speech by a representative speaker?) and have a particular significance in popular music: the question is not only whether cultural performances are seen 
sociolinguistically as authentic language use, but more importantly from the young adults' perspective, what counts as an authentic form of cultural or musical expression.

Chapter 4 looks at the transglossic practices of young adults as they relocalize varied filmic modes and linguistic resources within their daily linguistic practices. The speakers engage in 'filmic speaking' and display and recreate meanings through their filmic parodies, caricatures and modes while moving in and between movie resources. A typical example of this is the ways in which young Mongolians enact 'bushido speaking', producing Japanese 'samurai' style talking; or young Bangladeshi adults use a variety of means in written online environments to recreate 'filmic' ways of speaking from Hindi and Bangla films. This chapter also addresses questions of affiliation, arguing that popular culture engagement does not necessarily suggest any particular attachment to a cultural form or its purveyors but may equally derive from a more general circulation of cultural knowledge. This in turn can work in complex ways in relation to class and other forms of social organization. The apparent youth group affiliation negotiated with the use of filmic resources (and this applies across popular cultural genres more generally) cannot be assumed to be bilateral (certain groups of people are necessarily into certain forms of popular culture), but rather needs to be understood in relation to more diverse forms of desire and identification.

Chapter 5 shows how sports represent a major part of many young people's daily linguistic lives. From young Bangladeshis' fascination with Indian cricket stars to young Mongolia students' use of terms from Japanese sumo, these affiliations have both cultural and linguistic implications. While young speakers actively cheer for their favourite sports' team or athletes, they at the same time relocalize varied sports-associated linguistic and semiotic resources as a means of self-identification and peer-bonding. Sport in the contexts of Bangladesh and Mongolia is often bound up with young men's daily activities, with implications for particular performances of masculinity. Young males relocalize varied sports-associated linguistic and semiotic resources as part of their gendered and group solidarities. The transglossic take-up of sports thus becomes a key site for the production of a linguistic and cultural matrix of masculine and group identity.
Chapter 6 focuses on the transglossic practice of young adults and their involvement with various cyber-culture-associated resources, including the Internet and other new forms of network communication, such as online communities, social media, texting, chatting and emailing. Cyber speaking is not restricted only to online contexts but can also be stretched to offline contexts, as young people's Facebooked, Twittered and hashtagged lives cross easily between different modes. This chapter will also include a discussion of the notions of flows and locality, dealing in particular with the different conditions that afford or preclude forms of online engagement. Cyber-centric transglossia presents us with data which show inconsistency, disparity and uneven distribution of resources amongst young speakers. Not all speakers have control over or access to certain resources, since the uneven localizing processes of certain linguistic resources are tied to the uneven distribution of other resources.

In order to better understand the fluidity and dynamics in language created by the multiple codes, modes and resources within genres of popular culture, we argue in Chapter 7 that it is also important to look at multiple cultural and linguistic resources-'linguistic and cultural jamming'- that young people draw on from different popular culture genres and other generic sources. We further highlight the ways young speakers take up not only linguistic innovations with heavy borrowing from different popular culture genres, but any number of other multiple cultural genres that are pragmatically involved within their daily lives. One particular way in which this occurs is through parodic cultural mixing as these young adults produce exaggerated imitation of others' styles for comic and humorous effect. These parodies serve not only to mock the original sources and create humour at others' expense but also create lines of affiliation between and against different groups.

In Chapter 8, we conclude that young adults' sociolinguistic realities are mixed at their very core, and it is important to consider this reality in critical language pedagogies. Popular culture allows young adults to bring diversity to their language practices and traverse linguistic and cultural boundaries associated with their global peripheral positioning. Hence, in this book, we recommend that it is important in the area of language planning, language education policies, pedagogical practices and materials development to decrease the dependency on language epistemologies 
that promote divisions and singularisms in the form of monolingual instructional approaches or ideologies that promote English monolingualism at the expense of linguistic diversity, and to emphasize instead pedagogical approaches that engage with the diverse worlds of young people.

\section{Notes}

1. Even though English is taught as a compulsory subject across all levels of education in Bangladesh, the schools and colleges in the rural areas struggle to ensure sound English education because of lack of trained teachers, appropriate pedagogical practices, effective teaching materials, adequate infrastructure support and active engagement of students and 2. teachers in the learning process (Imam 2005; Sultana 2014b).

\begin{tabular}{ll}
\hline Transcription guide & \\
\hline $\begin{array}{c}\text { Elongated } \\
\text { pronunciation } \\
\text { CAPITALIZATION } \\
\text { and bold }\end{array}$ & $::$ \\
$((\ldots))$ & Stressed and enunciated \\
& $\begin{array}{l}\text { Non-linguistic features, explanation of utterances or } \\
\text { explanations of situations for readers' } \\
\text { comprehensibility }\end{array}$ \\
$<>$ & $\begin{array}{l}\text { Lower-paced than the surrounding utterances } \\
! ! ! / ? ? ?\end{array}$ \\
\hline
\end{tabular}

3. In other recorded conversations and interviews, Nayeem and Ashiq have often been found to pronounce English words with Bangla phonetic features.

\section{References}

Adorno, T. (1975). Culture industry reconsidered. New German Critique, 6 (Fall), 12-19.

Alim, S., Ibrahim, A., \& Pennycook, A. (Eds.). (2009). Global linguistic flows: Hip hop cultures, youth identities, and the politics of language. NewYork: Routledge.

Appadurai, A. (1990). Disjuncture and difference in the global cultural economy. Public Culture, 2(2), 1-24.

Appadurai, A. (1996). Modernity at large: Cultural dimensions of globalization. Minneapolis, Minnesota: University of Minnesota Press.

Appadurai, A. (2000). Globalization and the research design. Public Culture, 12 (1), 1-19.

Blommaert, J. (2010). The sociolinguistics of globalization. Cambridge: Cambridge University Press.

Blommaert, J. (2014). State ideology and language in Tanzania. Edinburgh: Edinburgh University Press.

Blommaert, J., \& Backus, A. (2013). Super diverse repertoires and the individual. In I. de Saint-Georges \& J. Weber (Eds.), Multilingualism and multimodality: Current challenges for educational studies (pp. 11-32). Rotterdam: Sense Publishers.

Bolander, B. (2017). Language and identity on Facebook. In S. Thorne \& S. May (Eds.), Language, education and technology: Encyclopedia of language and education (pp. 1-13). Springer International Publishing.

Brantlinger, P. (1983). Bread and circuses: Theories of mass culture as decay. Ithaca, NY: Cornell University Press.

Bucholtz, M., \& Hall, K. (2016). Embodied sociolinguistics. In N. Coupland (Ed.), Sociolinguistics: Theoretical debates (pp. 173-197). Cambridge: Cambridge University Press.

Choi, J. (2012). Multivocal post-diasporic selves: Entangled in Korean dramas. Journal of Language, Identity and Education, 11(2), 109-123.

Choi, J. (2016). Creating a multivocal self: Autoethnography as method. New York: Routledge.

de Bres, J. (2015). Introduction: Language policies on social network sites. Language Policy, 14(4), 309-314.

Dovchin, S. (2015). Language, multiple authenticities and social media: The online language practices of university students in Mongolia. Journal of Sociolinguistics, 19(4), 437-459. 
Dovchin, S., Sultana, S., \& Pennycook, A. (2015). Relocalizing the translingual practices of young adults in Mongolia and Bangladesh. Translation and Translanguaging in Multilingual Contexts, 1(1), 4-26.

Dovchin, S., Sultana, S., \& Pennycook, A. (2016). Unequal translingual Englishes in the Asian peripheries. Asian Englishes, 18(2), 92-108.

Gourlay, L., Hamilton, M., \& Lea, M. R. (2013). Textual practices in the new media digital landscape: Messing with digital literacies. Research in Learning Technology, 21, 1-13.

Grossberg, L. (1989). Pedagogy in the present: Politics, postmodernity, and the popular. In H. Giroux, R. Simon, \& contributors (Eds.), Popular culture, schooling and everyday life (pp. 91-115). Toronto: OISE Press.

Grossberg, L. (1992). We gotta get out of this place: Popular conservativism and postmodern culture. New York: Routledge.

Hoque, M. A. (2011). The influence of the local varieties on the sound patterns of English: A case study of Bangladeshi tertiary students. International Islamic University of Chittagong Studies, 7, 197-220.

Imam, R. S. (2005). English as a global language and the question of nation-building education in Bangladesh. Comparative Education, 41(4), 471-486.

Jacquemet, M. (2005). Transidiomatic practices, language and power in the age of globalization. Language \& Communication, 25(3), 257-277.

Jameson, F. (1998). Notes on globalization as a philosophical issue. In F. Jameson \& M. Miyoshi (Eds.), The cultures of globalization. Durham: Duke University Press.

Jones, R. (2009). Dancing, skating, and sex: Action and text in the digital age. Journal of Applied Linguistics, 6(3), 283-302.

Lee, J. S., \& Moody, A. (Eds.). (2012). English in Asian popular culture. Hong Kong: Hong Kong University Press.

Leppänen, S., Pitkänen-Huhta, A., Piirainen-Marsh, A., Nikula, T., \& Peuronen, S. (2009). Young people's translocal new media uses: A multiperspective analysis of language choice and heteroglossia. Journal of Computer-Mediated Communication, 14(4), 1080-1107.

Leppänen, S., Møller, J. S., Nørreby, T. R., Stæhr, A., \& Kytöla, S. (2015). Authenticity, normativity and social media. Discourse, Context and Media, 8 , $1-5$.

Martin, I. (2014). Philippine English revisited. World Englishes, 33(1), 50-59.

Moffatt, L., \& Norton, B. (2005). Popular culture and the reading teacher: A case for feminist pedagogy. Critical Inquiry in Language Studies, 2(1), 1-12.
Otsuji, E., \& Pennycook, A. (2010). Metrolingualism: Fixity, fluidity and language in flux. International Journal of Multilingualism, 7(3), 240-254.

Pennay, M. (2001). Rap in Germany: The birth of a genre. In T. Mitchell (Ed.), Global noise: Rap and hip-hop outside the USA (pp. 111-133). Middletown, Connecticut: Wesleyan University Press.

Pennycook, A. (2007). Global Englishes and transcultural flows. London: Routledge.

Pennycook, A. (2010). Popular cultures, popular languages and global identities. In N. Coupland (Ed.), The handbook of language and globalization (pp. 592 607). Oxford: Blackwell.

Pennycook, A. (2017). Translanguaging and semiotic assemblages. International Journal of Multilingualism, 14(3), 269-282.

Pennycook, A., \& Mitchell, T. (2009). Hip Hop as dusty foot philosophy: Engaging locality. In S. Alim, A. Ibrahim, \& A. Pennycook (Eds.), Global linguistic flows, hip hop cultures, youth identities, and the politics of language (pp. 25-43). New York: Routledge.

Phillipson, R. (1992). Linguistic imperialism. Oxford: Oxford University Press. Phillipson, R., \& Skutnabb-Kangas, T. (1996). English only worldwide or language ecology? TESOL Quarterly, 30(3), 429-452.

Phyak, P. (2015). (En)countering language ideologies: Language policing in the ideospace of facebook. Language Policy, 14(4), 377-395.

Pietikäinen, S., \& Kelly-Holmes, H. (2013). Multilingualism and the periphery. Oxford: Oxford University Press.

Rubdy, R. (2015). Unequal Englishes, the native speaker, and decolonization in TESOL. In R. Tupas (Ed.), Unequal Englishes: The politics of Englishes today (pp. 42-58). London: Palgrave Macmillan.

Scott, D. (1999). Refashioning futures: Criticism after postcoloniality. Princeton, New Jersey: Princeton University Press.

Sharma, B. K. (2012). Beyond social networking: Performing global Englishes in facebook by college youth in Nepal. Journal of Sociolinguistics, 16(4), 483-509.

Shusterman, R. (2000). Performing live: Aesthetic alternatives for the ends of art. Ithaca: Cornell University Press.

Sultana, S. (2013). Transglossic language practices: Young adults transgressing language and identity in Bangladesh. PhD diss. University of Technology, Sydney (UTS).

Sultana, S. (2014a). Heteroglossia and identity of young adults in Bangladesh. Linguistics and Education, 26, 40-56. 
Sultana, S. (2014b). English as a medium of instruction in Bangladesh's higher education: Empowering or disadvantaging students? Asian EFL Journal, 16 (1), 11-52.

Sultana, S. (2016). Language and identity in virtual space: Reconceptualisation of ELF. Journal of Asian Pacific Communication, 26(2), 216-237.

Sultana, S., \& Dovchin, S. (2017). Popular culture in transglossic language practices of young adults. International Multilingual Research Journal, 11(2), $67-85$.

Sultana, S., Dovchin, S., \& Pennycook, A. (2013). Styling the periphery: Linguistic and cultural takeup in Bangldesh and Mongolia. Journal of Sociolinguistics, 17(5), 687-710.

Swann, J., \& Maybin, J. (2007). Introduction: Language creativity in everyday contexts. Applied Linguistics, 28(4), 491-496.

Tagg, C. (2016). Heteroglossia in text-messaging: Performing identity and negotiating relationships in a digital space. Journal of Sociolinguistics, 20(1), 59-85.

Thorne, S. (2013). Digital literacies. In M. R. Hawkins (Ed.), Framing languages and literacies: Socially situated views and perspectives (pp. 193-218). New York: Routledge.

Varis, P., \& Blommaert, J. (2015). Conviviality and collectives on social media: Virality, memes, and new social structures. Multilingual Margins, 2(1), $31-45$.

Velghe, F. (2015). "Hallo hoe gaandit, wat maak jy?": Phatic communication, the mobile phone and coping strategies in a South African context. Multilingual Margins: A Journal of Multilingualism From the Periphery, 2(1), $10-31$.

\section{2 \\ Transglossia: From Translanguaging to Transglossia}

The transglossic framework that is central to this book brings together two related traditions: the recent blossoming of work under various 'trans' labels - the new translinguistics (translanguaging, translingual practices and so on) - and the older emphasis of Bakhtinian work on heteroglossia. The idea of transglossia refers to 'the fluid, yet stable, language practices of bilingual and multilingual societies that question traditional descriptions built on national ideologies' (García 2014, p. 108). The ways we look at the kinds of postings or interactions discussed in the previous chapter and below owe much to the recent shift in contemporary sociolinguistics towards the idea of translanguaging. Canagarajah (2013, p. 6) argues that the term translingual 'highlights two key concepts of significance for a paradigm shift': on the one hand, 'communication transcends individual languages', that is to say we use repertoires of linguistic resources without necessary recourse to the notions of languages; and on the other hand 'communication transcends words and involves diverse semiotic resources and ecological affordances', that is to say we draw on a wide set of possible resources to achieve communication. 